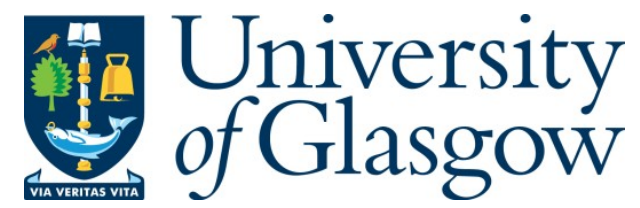

Doyle, G. (2010) Why culture attracts and resists economic analysis.

Journal of Cultural Economics, 34 (4). pp. 245-259. ISSN 0885-2545

Copyright (C) 2010 Springer Science+Business Media, LLC

A copy can be downloaded for personal non-commercial research or study, without prior permission or charge

Content must not be changed in any way or reproduced in any format or medium without the formal permission of the copyright holder(s)

When referring to this work, full bibliographic details must be given

http://eprints.gla.ac.uk/40439

Deposited on: 02 December 2014

Enlighten - Research publications by members of the University of Glasgow http://eprints.gla.ac.uk 
Final Author Version

Forthcoming (2010) in Journal of Cultural Economics, 34: 245-259

'Why culture attracts and resists economic analysis'

\section{Gillian Doyle}

Author's contact details:

Professor Gillian Doyle

Director, Centre for Cultural Policy Research

University of Glasgow

9 University Avenue

Glasgow

G12 8QQ

Telephone: 0141330 3806; Fax: 0141330 4142; Email: Gillian.Doyle@Glasgow.ac.uk

Keywords : research methods, media economics, multi-platform, creative destruction 


\section{Introduction}

Economics is a discipline at the heart of which quantitative methods typically feature very strongly but, by contrast, the realm of arts and culture can be seen as ephemeral, porous and in many respects not easily subject to the 'intrusion' of scientific analysis. Yet, newcomers to our field are frequently amazed by the rich volume of work and the array of topics, themes and approaches cultural economics has to offer. Although economics and culture may look like an uncomfortable marriage, the appetite amongst potential end-users for economic research into cultural and creative industries is stronger today ever it has been in the past. Oddly, culture seems to both attract and resist economic analysis.

This paper considers some of the appeals of conducting scholarly research work in cultural economics and, also, the difficulties and challenges that potentially lie in wait. It examines what is distinctive about the field and, as well as discussing associated problems (drawing on ideas previously raised in joint work with Simon Frith (Doyle and Frith, 2006)), it highlights the opportunities we enjoy to provide insights that fascinate and that extend understanding in relation to organisation and use of cultural resources. By way of illustrating some of its core themes, this paper presents and analyses findings from recent research work on economics of media and multi-platform growth strategies in the television broadcasting sector.

The overall structure of the article involves, first (in sections 2-4), an examination of what is special about carrying our research in media and cultural economics; second (in section 5), an analysis of findings from research on multi-platform strategies in the television broadcasting industry; and finally (in sections 6-7), recapitulation on challenges and opportunities facing researchers interested in economics of culture.

\section{What is different about culture?}

Cultural economics research can be understood simply as research that concerns itself with economic aspects of culture. But this side-steps a host of thorny issues of definition around the concept of 'culture' (Hesmondhalgh, 2002). Culture is a fluid term and despite many brave attempts to identify what it is exactly and which industrial sectors it includes, the boundaries around which activities count or not as 'cultural' are not entirely clear. Many scholars and theoreticians would steer us towards understanding 'culture' as being about the symbolic structures (rituals, artifacts etc) that imbue our everyday activities with some kind of meaning or significance and value (Williams, 1981). But the meanings and symbols we know as culture are profuse and very varied, as are modes of provision and consumption of culture, which implies that the potential ambit of a field devoted to researching and understanding economics of culture might be very wide indeed.

Some definitional work by economists has achieved prominence in recent years and, in particular, David Throsby has identified and described cultural provision in terms of activities that involve 'some form of creativity in their production'; and where symbolic meanings are important; and where outputs embody intellectual property (Throsby, 2001: 4). This work is very helpful in delineating the contours 
of the cultural sector and its outputs and has been widely adopted within discourse about public policy. But it remains that conceptions of what counts as culture are varied and, likewise, economic research in the area of culture is diverse. As Towse and others have acknowledged (Towse, 2010), economics is, itself, a somewhat varied field involving different methodological approaches and traditions. And also, it is not just economists whose research work is apt to shed light on economic aspects of culture, but also scholars from other disciplines including cultural studies, management, business studies, sociology, and urban studies.

So, as is reflected in the spread of literature which comprises and typifies the field of cultural economics, this is an area characterised by diversity. And, shaped by the interests of industry players from a range of sectors (e.g. music, television, theatre, museums and galleries), by arts and cultural practitioners and administrators, and by policy-makers as well as scholars, the contexts from which emerge those research questions that define our subject area are also diverse. But, despite that diversity, most of us who carry out research related to economics of culture will probably agree there are aspects of these sectors which, compared with other areas of economic activity, are a bit 'different' and special.

\section{Media - A unique business}

Within the broad ambit of cultural economics, heritage and arts (literature, drama, dance, visual arts etc) often feature strongly but media activities (i.e. broadcasting, film, newspapers, magazines, online publishing etc) also represent a substantial and growing area of interest. The media industry is unique, and yet many of the features and concerns that mark out economics of media as special - the uncertainties and irrationalities that characterise production of creative output; the unusual public good aspects of media content - resonate with those confronting economic enquiry into other dimensions of culture.

The predominant concern underlying most studies in media economics is how best to organise the resources available for media provision. Economists want to know are firms producing the right sorts of goods and services and are they being produced efficiently? But answering these questions can be tricky in the context of media. One problem, as noted by Alan Peacock (1989) whose work on economics of broadcasting has been exceptionally influential, is that the welfare impacts associated with communicating with mass audiences are not easily incorporated within the framework of standard quantitative economic analysis.

The business of producing and distributing media involves supplying messages and ideas and this, inevitably, involves significant public welfare implications. On account of this unique feature, research within media economics stems not only from traditional economics but also from the perspective called critical political economy. The arguments for adopting a more normative approach towards analysis of media are summarised aptly by Douglas Gomery (1993: 198) who suggested that 'studying the economics of mass communications as though one were trying to make toaster companies run leaner and meaner is far too narrow a perspective'. 
It is sometimes said that media operate in 'dual product' markets (Picard, 1989: 17-19). This refers to the way that media generate two different sorts of outputs: first, media content (i.e. programmes, news stories etc) and, second, media audiences (attracted by the content). The latter - audience attention - is routinely packaged and traded. Often this provides a vital source of income for media content suppliers. In recent years, however, the sale of audience attention has become somewhat dis-located from investment in professionally crafted original content production because of the advent of a new layer of online intermediaries (search engines, aggregators, social networking sites, etc) and, as discussed in section 5 below, the consequences for some incumbents in the media sector have been extremely detrimental (Doyle, 2010).

The fact of operating in a so-called 'dual product market' is, in itself, a bit unusual but also one of the duo of outputs - media content - exhibits a number of interesting peculiarities when compared with 'normal' goods (Collins, Garnham and Locksley, 1988). A key distinguishing feature of, for example, a television programme is that its value for consumers is tied up in the messages it conveys, rather than with the material carrier of that information (i.e. the radio spectrum, the digital file, etc). So the essence of what provides value within a television broadcast is not actually used up in the act of consumption. This public good characteristic of not being destroyed in the act of consumption is, of course, shared more widely with other cultural goods and since it allows the same output to be supplied over and over again at no extra cost, both media and other forms of cultural output (the song that has been sung, the story that has been told etc) seem to, in some senses, whittle away at the cornerstone upon which the rules of economics are based - scarcity. Albeit that creation of an original prototype involves investment of costly resources, the subsequent ability to enable an infinite number of users to enjoy that output is not liable to the constraints usually imposed by scarcity.

\section{Challenges for researchers}

For the researcher in media and cultural economics, the unusual qualities of output in these areas and any associated awkwardness in applying standard frameworks of analysis are not the only source of challenge. To the extent that personal resources of 'talent' or 'star quality' - with all the difficulties of gauging and measuring that these entail - are key to the success of any given output, the very processes involved in the production and creation of value within these industries can, at times, seem almost resistant to rational analysis. The market value of a cultural commodity, as with fashion items, is not predictable. Earnings will not necessarily rise nor diminish in a neat trend - a song or film or artwork or television programme might be more valuable as a 'classic' than it ever was as a new release (Doyle and Frith, 2006: 566). Production and investment behaviours centred around risk-spreading and cross-

subsidy in cultural industries can, in any other context, seem irrational, given the high level of expenditure on development of products that fail.

Mainstream economic theories and assumptions do not always provide a made-to-measure framework for understanding and modelling cultural activities. This is, of course, a source of opportunity as much 
as challenge for media and cultural economists. The development of cultural economics has, from the outset, been propelled by influential work that embraces and theorises the exceptional contingencies of cultural provision successfully. Examples of this include work on 'cost disease' in the arts (Baumol and Bowen, 1966), or on 'cultural discounts' (Hoskins, McFadyen and Finn, 1997), or on the role of contracts in addressing incentive problems in creative industries (Caves, 2000). So, to lose sight of what is different and special about culture is to risk consigning cultural economics to obsolescence.

Another sort of challenge facing researchers interested in economics of culture is that it can be difficult to come up with any wholly convincing measure of economic performance. Within economics of media, the central unit of analysis for a great deal of research is the firm. Researchers are interested in finding out whether organisations and the resources they are utilising are being managed efficiently. But what measures can we use? Looking at profits or ROCE seems rather limited. How can we measure and compare the performance of organisations in differing circumstances and over time?

One problem with devising a suitable performance measure stems from what some economists have described as the 'multi-dimensional' nature of performance (Wirth and Bloch, 1995: 18), and this is particularly a problem when it comes to media and cultural industries. Different constituencies of interest such as senior management, employees, shareholders, customers, and 'the public' are prone to differing points of view about what any given organisation's goals are, or ought to be. This is probably true in any sectoral setting but is especially true in industries involved in cultural provision.

The fact that cultural output has the potential to impact, whether for better or worse, on public welfare means that in some quarters at least, even in relation to the most commercial and profit-maximising of entities, expectations as to how cultural resources ought to be organised and utilised may be hazy, divergent and even contradictory. The complex and multi-faceted nature of economic performance in the context of culture allows no easy route towards conceptualising nor towards operationalising research whose aim is to quantify the effectiveness of firms involved in creating and supplying cultural output. Cultural output can be classified and quantified in numerous ways but, as Peacock and others have pointed out in the past, translating this data into meaningful information about welfare impacts remains extremely problematic (Cave, 1989; Peacock, 1989; Throsby, 2001, Bragge and Snowball, 2007).

\section{Negotiating Creative Destruction: A case study of UK television}

Some sense of the attractions and pitfalls of conducting research work in the area of media economics can be gleaned by considering an example. So this section reports and analyses findings from an empirical research study on the UK television industry. In section 6 below, these findings are related to the wider theme of challenges confronting researchers.

Technological change provided the background to this particular study, as many others in media and cultural economics. An investigation of UK television broadcasters was embarked on in 2009 and it aimed to shed light on an approach that has become very widespread amongst incumbent media 
organisations - namely, multi-platform distribution. Across the media, many firms have responded to digital convergence by adopting a multi-platform strategy or so-called '360-degree' strategy in relation both to production and to exploitation of their content assets. But is a multi-platform strategy enough to save media firms from what Schumpeter (1942) described as 'the gales of creative destruction'? In what ways, if any, is this approach improving the economics of supplying content?

Focusing on the UK television industry as a case study (and mainly on the BBC, Scottish Television, ITV, Channel Four and MTV), the investigation involved analysis of financial accounts and interviews with television executives involved in corporate planning, strategic management, content acquisition and management of digital operations. Evidence was gathered in relation to the main perceived advantages driving the migration towards multi-platform distribution and the costs involved. The main aim was to find out in what ways switching to a multi-platform approach is enabling broadcasters to exploit their resources and serve audience demands more effectively.

Numerous earlier studies have concerned themselves with the ways that new communications technologies impact on media markets (Chan-Olmsted, 2006: 251-2; Dennis, Warley and Sheridan, 2006; Küng, 2008; Küng, Picard and Towse, 2008). This research set out to look at the multi-platform strategies in the broad context of the notion of 'creative destruction'. The term creative destruction was first used by Austrian economist Joseph Schumpeter to describe the process whereby technologies change and new innovations emerge that then force existing businesses either to adapt or to die out (McCraw, 2007). As entrepreneurs innovate, this brings opportunities and growth but it also results in existing products and services losing ground and so the value of large dominant firms who fail to transform in response to technological change will be destroyed. Adherents to the theory of evolutionary economics that was inspired by Schumpeter argue that innovation offers an important source of advantage to firms as they seek to compete with each other (Metcalfe, 1998:17).

For Schumpeter, advances in technology and the associated opportunities that entrepreneurs see and sieze upon to profit from these advances is what fuels a continuous and ongoing process of creative destruction which, in turn, brings economic growth. Innovation, economic advancement and demise of existing businesses are inextricably intertwined with one another. Numerous earlier studies and economic surveys offer general support for the Schumpeterian vision that the phenomenon of constant restructuring and replacement of old products and businesses by new ones is central to economic growth in market economies (Aghion and Howitt, 1992; Caballero, 2006). The potential relevance of this conceptual approach to developments in the media sector has also been noted by business writers and scholars in media economics (Chan-Olmsted, 2006: 253; Küng, Picard and Towse, 2008: 25-6).

The concept of creative destruction appears to provide a useful explanatory framework both for the dynamism of media industries in general and, more specifically, in relation to the profound impact of recent technological changes. An obvious and commonly cited example of creative destruction relates to the music sector where the progress of time has been marked by a succession of advances in audio formats, from gramaphone to vinyl records to the arrival of CDs which are now being usurped by MP3 digital files. Each successive innovation has brought opportunity, success and growth for some 
players. But, as evidenced by the deteriorating position of record companies in the wake of digital MP3 file-sharing, innovation can also spell destruction for those unable to adapt (Dhar and Sundarajan, 2009). Many other sectors involved in content production and distribution, including linear broadcasting, also appear to be caught up in the gales of creative destruction. In the newspaper industry, innovative new products such as the Huffington Post have rapidly achieved popularity and success while amongst conventional titles numerous closures have taken place, largely as a result of technological advances and altered consumption and advertising patterns (Patterson, 2007; Slattery, 2009). In magazine publishing too, many businesses and titles are struggling to innovate in the face of threatened extinction (Luft, 2009).

At the root of the current upheaval is digital convergence. The term 'convergence' is used in many different ways (Jenkins, 2006) but, in the current context, is intended to denote the use, right across media and communications industries and in all stages of production and distribution of content, of common or shared digital technologies. The convergence of technologies and the ways in which this has brought together sectors of activity that previously were seen as distinct are widely recognized as major forces affecting industry structure (Drucker, 1985: 75-6). Convergent technologies have spurred on the development of digital platforms, new forms of content and of converged devices. Convergence has impacted not only on content and delivery but also, as many earlier studies have shown, on the operational and corporate strategies of media organizations (Küng, 2008). Digital convergence and growth of the internet have provided extensive opportunities for innovation in the media sector - thus acting as a 'creative' force - but also, as evidenced by recent closures amongst newspapers, these developments have engendered difficulty and even demise for some market incumbents.

Schumpeter's view was not only that creative destruction is an inherent feature of capitalist societies but also that it is a beneficial one (1942). In a similar vein, Schumpeter and other economists (such as Hayek and Robbins) have argued that recessions serve the useful purpose of encouraging a reallocation of resources away from less productive activities (as reflected in higher company liquidations) and towards what are ultimately more productive economic activities. Thus in periods of technological change and of recession such as are being experienced by media companies in 2009-2010, the combined forces of liquidationism plus creative destruction are apt to speed the pace at which slow adaptors get weeded out.

It is worth distinguishing between creative destruction and the possibility of 'destructive' destruction i.e. a phase in which businesses are eradicated but without any positive benefits being created. If the innovation that allows a firm to displace market incumbents is based on practices or activities that are not conducive to the wider economic or public good (if, say, it involves pollution) then what appears to be creative destruction may, in fact, turn out to be something else. Correct diagnosis is important from the point of view of ensuring an appropriate policy stance that advances collective societal interests.

Digital convergence is associated with countless claimed gains for citizens and consumers related to the arrival of innovative services, more flexibility and control over how and when to access media plus greater opportunities for participation. At the same time, the destructive impact of digitization and the 
internet on intellectual property rights (because of the ease and prevalence of illegal copying) has caused some to question whether changes sweeping across content provision industries amount to creative destruction or 'just plain destruction' (Liebowitz, 2006: 1). The siphoning off of audiences by online service providers such as Google and You Tube who frequently do not own and have not borne the costs involved in producing content represents a serious threat to the current and future revenuegenerating ability of broadcasters and other media content suppliers worldwide.

Opinions differ as to whether digital convergence and the internet count as revolutionary and disruptive rather than just evolutionary technological changes, but it is widely accepted that significant technology transitions such as these are 'always highly problematic for incumbent players' (Küng, Picard and Towse, 2008: 33). Even so, firms across many sectors have historically survived processes of creative destruction and, in the media sector, the challenge of adapting to technological change is certainly nothing new (Carlaw et al, 2006). If, as some have argued, most media incumbents can be expected to survive (Cole, 2008), this requires that operational and corporate strategies must be adapted successfully to the era of convergence.

Via a study of UK-based television broadcasters, the research examined adoption of a multi-platform outlook as a specific strategic response on the part of incumbent media firms to technological change. In the television broadcasting sector in most developed economies, many if not most players have found themselves under pressure to embrace multi-platform distribution as a means of retaining and building audiences in the face of vastly increased competition (Khouri, 2008). Virtually all television companies in the UK speak of having a '360-degree' approach to content acquisition and distribution (Parker, 2007). A 360-degree commissioning strategy involves considering, from the earliest stages of conceptualization of a new content property, what potential exists for that property to be distributed and exploited across multiple digital platforms and formats (including online and mobile), either simultaneously or sequentially, and in whatever pattern enables audience value to be maximised.

Findings emerging from the study indicated that, in the UK at least, the view that the business of supplying television is really a multi-platform rather than a single platform activity has been embraced by public service providers and commercial players alike. The way in which a multi-platform approach has altered processes of acquiring news programmes was summarized by one BBC Executive $^{1}$ as follows:

Normally what we would have done is say 'let's commission a TV series' whereas now with 360 degree commissioning, we are much more likely to say 'let's commission an idea'. Let's let someone come to us with an idea and then let's tease it out to see how small or big or possible it might be.

In the commercial sector, London-based Viacom subsidiary MTV provides a good example of a broadcaster that has consciously overhauled its organisational culture so as to better execute strategies that capitalize on a multi-platform approach. Whereas up until a few years ago it was generally

\footnotetext{
${ }^{1}$ Small, interviewed in Glasgow in 2009.
} 
assumed that television was the sole focus, this perception has now been superceded by a new understanding of the nature of the business, according to the Head of Digital at MTV Networks ${ }^{2}$ :

The future of media companies isn't just in making movies, broadcasting TV and making TV. It also is making console games like Rock Band ... and games online ... and virtual worlds, which have millions of people communicating with each other within our brand but has got nothing to do with TV... MTV in the UK is a completely 360 degree media owner ... We're not a broadcaster; that's just part of what we do. We make programmes, we own brands and we media-cast multi-platforms..

This sort of thinking has percolated very widely across the UK television industry. And it is not companies' thinking that has changed but also the balance of their activities, their flows of investments and in many cases their corporate structures. Companies, including the BBC, have re-structured in many cases substantially in order to 'wherever possible .. think cross-platform' (Thompson, 2006: 12). One aspect of the investigation focused on how digitisation has affected job flows within media companies.

Across the UK television industry, the impetus to invest in development of multi-media and online businesses has been reflected in a progressive increase over time in the number of employees devoted to such activities. A commonly used yardstick for measuring the intensity of processes of creative destruction is that of factor reallocation and, especially, job flows (Caballero, 2006). This approach has been used, for example, by Davis, Haltiwanger and Schuh (1996) in analyzing job flows within the US manufacturing sector. Albeit that systematic data about job flows in the television industry is in short supply, and that comparison is hampered by inconsistencies in data between companies and over time, the information set out in Table 1 below, based on leading UK broadcasters ITV and Channel 4, provides a useful picture of the way in which the sector is responding to technological advances through attrition and disappearance of jobs in some areas while, in functions related to the internet and digital or future media, the flow of new jobs has increased markedly. The way in which, within ITV and Channel 4, existing job functions have disappeared or been destroyed in order to make way for new ones created is suggestive of processes of adaptation that, across the newspaper industry as a whole, seem to be occurring much more widely, although this needs to be tested by further empirical research.

Table 1: Segment Analysis of Employees at selected UK broadcasters 2006-2008

\begin{tabular}{|lrrr|}
\hline Year to 31 December & \multicolumn{2}{l}{2006} & 2008 \\
\hline ITV plc & 135 & 286 & 373 \\
Average employees in Online & 5,957 & 5,700 & 5,597 \\
Total employees at ITV & $\mathbf{2 . 3 \%}$ & $\mathbf{5 . 0 \%}$ & $\mathbf{6 . 7 \%}$ \\
Online as \% of total employees & & & \\
Channel $\mathbf{4}$ & 111 & 137 & 146 \\
Average employees in New/ Future Media & & & \\
\hline
\end{tabular}

\footnotetext{
${ }^{2}$ O'Ferrall, interviewed in London in 2009.
} 
Source: Based on figures from annual financial statements for ITV plc and Channel 4.

While changing patterns of staff activity within the UK television broadcasting sector indicate a substantial level of creative and financial investment into online and multi-media activities, the level of returns to investment earned from these activities has been mixed so far. Some niche players, including MTV, report success in generating marginal revenues that far outstrip the costs involved in multi-platform distribution. At ITV however, the share of revenue accounted for by the online division was only $1.5 \%$ in 2008, compared with an average headcount in online of $6.7 \%$ of total staff (ITV, 2009: 58). Likewise at Channel 4, the average headcount involved in 'future' media activities in 2008 was $16.1 \%$ compared with revenues equivalent to only $3.7 \%$ of the company's total earned by this division (Channel 4, 2009: 99).

However costly it may be, the need to innovate and to adapt in response to technological change and in order to survive and stay ahead of rivals is very widely recognized as a driving imperative for firms in free market economies (Baumol, 2002). As earlier studies have shown, pressures to innovate and remain in step with emerging technologies are also strongly felt in the public service broadcasting sector where conceptions of the key purposes public service provision ought to fulfill in a digital era have generally grown ever more demanding (Bennett, 2008; Duncan, 2006; Graham, 1999; Enli, 2008).

While few conclusions can be drawn at this early stage in relation to whether multi-platform strategies will help save incumbent media firms from creative destruction, the experience of UK-based broadcasters very clearly suggests that adjustment and innovation based around switching to this approach is generally based on the promise of advantages in two main areas. One relates to providing more and improved access to content while the other relates to new forms of audience engagement.

With regard to how multi-platform facilitates improved exploitation of content, many TV companies are trying to use internet and mobile platforms primarily as a way to develop up online distribution services for their own content. Examples of this, in the UK context, are the BBC iPlayer or 4OD content catch-up services, or MTV's use of its website to guide viewers through to iTunes where they can purchase MTV videos. Similarly, the Hulu online video service in the US owned by NBC, Fox and Walt Disney which has grown rapidly in popularity since its launch in 2007 allows shows from the major networks to be streamed (Edgecliffe-Johnson and Menn, 2009). A key incentive that supports the migration beyond television broadcasting or newspaper publishing or magazine publishing towards, instead, multi-platform publishing or distribution is the opportunity to widen reach and squeeze more value out of content. Re-cycling and 'windowing' of television content across additional audience segments, although by no means new, makes a great deal of economic sense (Anderson, 2006; Owen and Wildman, 1992; Murray, 2005).

But the desire to use and exploit content more effectively is not the only motivation at play. Another way that multi-platform digital distribution potentially creates advantage is that it allows for different 
modes of engagement with viewers. Thanks to online distribution, increased capacity, improved searchability etc, audiences have been empowered in terms of deciding what to watch, where and when. And use of the digital return path can fuel a much greater sense of participation and involvement with television content on part of audiences such as, in the case of televised 'events' and contests and competitions, through web forums and systems of voting (Roscoe, 2004, Ytreberg, 2009). The additional avenues through which audiences can be engaged will, in some cases, bring new revenue streams - e.g. income from telephone voting. But closer engagement with audiences brings other sorts of opportunities too (Caldwell, 2003). For instance, through the use of online teasers and tasters ahead of a show, some broadcasters are finding ways to manage their audience flow more effectively in order to build and maximize the overall level of attention, and also to guide viewers towards engaging with content and content brands via whichever form of expression of that content will deliver the best return.

Another potential advantage is that, thanks to the digital return path, systems for signaling preferences back to suppliers have improved greatly (Shapiro and Varian, 1999: 34). Television content suppliers can, if they want to, find out much more about the needs and preferences of individuals and audiences. Findings from this particular study of UK players suggest that some broadcasters can and do use this intelligence in very immediate ways to shape their production decisions. This greater ability to match supply to audience desires and needs opens out the possibility of much more effective use of the available universe of media content over time.

\section{Challenges for researchers re-visited}

Findings emerging from the above empirical study are now considered in the context of the wider themes for this article - the 'specialness' of culture and attendant challenges and opportunities for those carrying out economic research into economic aspects of culture. Experiences amongst the sample of UK television companies examined suggest that one of the key advantages driving incumbent media firms towards multi-platform distribution is the ability to get more value out of content. On account of multi-platform dissemination, the volume of outputs and content consumption opportunities being supplied has vastly increased, reflecting wider cross-platform access to content and tendencies towards generation of multiple versions of narratives out of individual stories and content properties.

Re-versioning of content is easier, constraints over distribution capacity are much reduced and so dissemination of content across additional platforms such as the internet is now fairly widespread as a strategy.

However, the researcher who wants to interrogate whether or not multi-platform approaches have induced greater efficiency in processes of producing and supplying media is faced with some fairly complex problems. This is because, as mentioned earlier, judgements about the efficiency of one set of arrangements for provision of media as opposed to another are pretty much inseparable from some sort of judgement about the welfare impacts that the differing patterns of provision would give rise to. The fact that the volume of content outputs and consumption opportunities has vastly increased is not necessarily indicative of an improved experience for audiences. Indeed, the opposite may be true. 
In this study of the UK television industry, executives in both the commercial and the non-commercial sector conceded that, at a time when content budgets have been static or diminishing because of recession, the most practical way to meet audience demand and advertiser demand for multi-layered 360-degree output from within constrained budgets is to focus on fewer, high impact ideas. At the $\mathrm{BBC}$, for example, the formula 'fewer, bigger, better' was adopted as part of its restructuring to a multi-media entity. This approach clearly acknowledges that breadth must suffer in order to support more innovative and potentially high impact content proposals. In the commercial sector, it is also evident that, exacerbated by recession, many broadcasters have embraced the need for greater selectivity in content decisions as part of their digital strategies. Thus, rather than contributing towards greater diversity and choice, multi-platform distribution is in some senses liable to encourage standardization around safe and popular entertainment themes and brands (such as Pop Idol and Big Brother) that achieve high visibility and impact in a multi-platform context.

This finding echoes conclusions from another major empirical study carried out at Goldsmith's College in London into how digitization is affecting news production. The Goldsmith's study found that the internet has not, in fact, expanded the news we read or hear nor changed mainstream news values and formats (Fenton, 2009). A relentless re-cycling of content across platforms, while making it easier to access news at all times, may at the same time be harmful to quality and diversity.

To the extent that multi-platform distribution, while extending opportunities for consumption of content, also encourages strategies of brand extension and promotes the 'market ubiquity' of a limited number of big name television content properties, can we safely conclude that this approach engenders an economically improved use of resources?

While any threat to diversity of content is naturally of concern in terms of pluralism, the chief problem this example is intended to highlight is not narrowing of diversity per se but rather a fundamental difficulty that besets the researcher working in cultural economics in establishing whether one sort of outcome is better than another. If, say, through a reallocation of resources, a television production company finds it can increase the number of hours of output it creates from an unchanged budget, is it safe - in the absence of recourse to issues of quality and aggregate welfare - to conclude that the new package of outputs amounts to a better use of resources than before?

The problems of evaluating and comparing the utility in one package of content outputs rather than another are very difficult to surmount and, I would argue, these problems are made no easier by the arrival of digital delivery platforms and of new modes of engagement with media content. At present, the proxies most commonly relied upon for assessing utility usually involve some quantification of audience time. With a television service for example, the utility it generates might be crudely estimated based on the number of viewers for the service in question multiplied by the amount of time spent viewing. And for radio, the total number of listeners multiplied by amount of time spent listening provides a useful if limited yardstick in relation to audience value. However, when it comes to new interactive forms of media, because length of time spent online may indicate difficulty finding what it is you are looking for (a negative experience) as opposed to engagement with the content that interests 
you (a positive experience), even a measure based crudely on calculation of audience time is not necessarily going to provide a workable basis for analysis nor for comparison.

\section{Opportunities}

Carrying out research into economic aspects of culture provides numerous and ongoing opportunities to negotiate practical and conceptual challenges. At the same time, interest in cultural economics is growing internationally, as is evident from increased conference activity and from more research and teaching right across the field. Increased levels of interest and engagement with our subject area over recent years are partly a reflection of the 'peculiarities' of cultural provision which, for many of us, serve as an inspiration to participate in developing innovative research.

But, from about 2000 onwards, growing opportunities for cultural economists have also undoubtedly been fuelled by a widespread re-evaluation of the role arts and culture may play in supporting economic growth. Previous perceptions of arts and culture as inherently worthy but economically unproductive activities have changed and now creative and cultural industries are seen as key drivers of growth in the wider economy (Hutton et at, 2007: 16). As a result, there is a considerable interest in research work that explores links between creative and cultural industries and the wider economy and that demonstrates the economic impact of investment in arts and cultural activities. Demand for research into economic aspects of creative and cultural industries from end-users such as state and local authorities has never higher than it is today. The creative industries turn has ushered in an era of unprecedented opportunity for cultural economists.

However, as has been argued throughout this paper, the use of economic approaches towards evaluating arts and culture is not unproblematic. Many others working in the area of cultural economics have pointed to the dangers and the pitfalls of trying to apply the tools and measures of economics to the arts such as, notably, Arjo Klamer (1996). So whether vastly increased demand for economic impact studies is cause for celebration is questionable. Bragge and Snowball (2007), in a paper concerned with studies of the impact of arts festivals in South Africa, argue for an approach that to me makes good sense. As cultural economists we should embrace opportunity while also keeping methodological and conceptual issues high on our agendas and working to refine and improve our methods. I would add that full exploitation of available opportunities is not only contingent on development of effective techniques for analysis and measurement but also on good communications an ability to express our ideas in ways accessible to non-specialists and non-economists.

One final reflection on opportunities open to scholars working in the area of cultural economics relates to the wider good served by academics' participation in debates about media and about cultural policy. On some of the questions cultural economists will be interested in (on, for example, rights ownership, or the impact of special support measures for content creators, or competition and ownership) it may be the case that the research and data of greatest pertinence will be generated by the organisations that produce and supply cultural goods or by their trade associations. Industry-led research is important but dangers will arise if, in arriving at a view about what policies are needed to accommodate market 
changes or developments in technology, governments rely too heavily on industry itself to provide an interpretation of economic realities. So, in assessing the opportunities we collectively enjoy, let us not overlook the role and the value that independent scholarship in the area of economics can bring to debates about media and about cultural policy. 


\section{References}

Aghion, P and Howitt, P (1992), 'A Model of Growth through Creative Destruction', Econometrica, 60 (2): 323-351.

Anderson, C (2006), The Long Tail: Why the Future of Business Is Selling Less of More, New York: Hyperion.

Bennett, J (2008), Interfacing the Nation, Convergence: The International Journal of Research into New Media Technologies, 14 (3): 277-294.

Baumol, W and Bowen, W (1966), Performing Arts: The Economic Dilemma, Hartford, CT: Twentieth Century Fund.

Baumol, W (2002), The Free-market Innovation Machine: Analyzing the Growth Miracle of Capitalism, Princeton: Princeton University Press.

Bragge, B and Snowball, J (2007), 'Why arts practitioners love economic impact studies and cultural economists hate them', Paper presented at $9^{\text {th }}$ Conference of AIMAC, University of Valencia, July 2007. Caballero, R (2006), The Macroeconomics of Specificity and Restructuring, Yrjo Jahnsson

Lectures, Cambridge, MA: MIT Press.

Caldwell, J (2003), 'Second Shift Media Aesthetics: Programming, Interactivity and User Flows' in Caldwell J and Everett A (Eds), New Media: Theories and Practices of Digitextuality, London: Routledge, pp 127-144.

Carlaw, K. et al (2006), 'Beyond the Hype: Intellectual Property and the Knowledge Society/ Knowledge Economy', Journal of Economic Surveys, 20 (4): 633 - 690

Cave, M. (1989), 'An Introduction to Television Economics', In Hughes, G. \& Vines, D. (Eds). Deregulation and the Future of Commercial Television (pp. 9-37). David Hume Institute Paper No. 12. Aberdeen: Aberdeen University Press.

Caves, R (2000), Creative Industries: Contracts between Art and Commerce, Cambridge, MA: Harvard University Press.

Chan-Olmsted, S (2006), 'Issues in Media Management and Technology', in Albarran, A. Chan-Olmsted, S. and Wirth, M (eds), Handbook of Media Management and Economics, Mahwah, NJ: Lawrence Erlbaum Associates, pp 251-273.

Channel 4, (2009), Report and Financial Statements 2008, London: Channel 4 Television Corporation Cole, J (2008), Creative destruction in the digital media age, Insead Knowledge, Downloadable at:

Collins, R, Garnham, N and Locksley, G (1988), The Economics of Television: The UK Case, London: Sage Publications.

Davis, S. Haltiwanger, J. and Schuh, S. (1996), Job Creation and Destruction, Cambridge, MA: MIT Press.

Dennis, E. Warley, S. and Sheridan, J. (2006) 'Doing Digital: An Assessment of the Top 25 US Media Companies and their Digital Strategies', The Journal of Media Business Studies 3(1): 33-63.

Doyle, G and Frith, S (2006), 'Methodological Approaches in Media Management and Media Economics Research', Chapter in Handbook of Media Management and Economics, Albarran A \& Chan-Olmsted S (Eds), Mahwah, NJ: Lawrence Erlbaum Associates, pp 551-570.

Doyle, G (2010), 'From Television to Multi-platform: Less from more or more for less?' Convergence: The International Journal of Research into New Media Technologies, 16 (4) November. 
Dhar, V and Sundarajan, A (2009) 'Managing in a Downturn: Plugging in to Transformation', Financial

Times, Special Supplement on Mastering Management, February 5, accessed at:

www.ft.com/cms/s/0/1f509532-f256-11dd-9678-0000779fd2ac.html

Drucker, P (1985), Innovation and Enterprise, Oxford: Elsevier.

Duncan, A (2006) 'Maximising Public Value in the "Now" Media World' in Sinclair, C (ed) (2006), Transforming Television: Strategies for Convergence, Glasgow: The Research Centre, pp18-29.

Edgecliffe-Johnson, A and Menn, J (2009), 'Hulu might charge viewers not to see ads', Financial Times, May 29, accessed at: www.ft.com/cms/s/0/cd001bbe-4c77-11de-a6c5-00144feabdc0,s01=1.html

Enli, G (2008), 'Redefining Public Service Broadcasting: Multi-Platform Participation', Convergence: The International Journal of Research into New Media Technologies, 14 (1): 105-120.

Fenton, N (Ed) (2009), New Media, Old News: Journalism and Democracy in the Digital Age, London: Sage.

Gomery, D (1993), The Centrality of Media Economics, Journal of Communication, 43 (3): 190-198.

Graham, A (1999), 'Broadcasting Policy in the Multimedia Age', in Graham et al (eds), Public Purposes and Broadcasting: Funding the BBC, Luton: University of Luton Press, 17-47

Hesmondhalgh, D (2002), The Cultural Industries, London: sage.

Hoskins, C. McFadyen, S. and Finn, A (1997), Global Television and Film: An Introduction to the Economics of the Business, Oxford: Oxford University Press.

Hutton, W, et al (2007), Staying Ahead: the Economic Performance of the UK's Creative Industries, London: The Work Foundation.

ITV plc (2009), Driven by Content: Report and Accounts 2008, April 2009, London: ITV plc.

Jenkins, H (2006), Convergence Culture, New York: New York University Press.

Khouri, C (2008), 2008 Trends to Watch: Media and Broadcasting Technology, London: Datamonitor.

Klamer, A (Ed) (1996), The Value of Culture: On the Relationship between Economics and Arts, Amsterdam: Amsterdam University Press.

Küng, L (2008), Strategic Management in the Media, London: Sage.

Küng, L. Picard, R and Towse, R (2008), The Internet and the Mass Media, London: Sage.

Liebowitz, S (2006), File Sharing: Creative Destruction or just Plain Destruction? Centre for the analysis of Property Rights Working paper No 04-03. Available at:

Luft, O (2009), 'Stuck in the middle', Guardian, Media Supplement, January 5 2009, at p5.

McCraw, T (2007), Prophet of Destruction: Joesph Schumpter and Creative Destruction, MA: Harvard University Press.

Metcalfe, J (1998), Evolutionary economics and creative destruction, London: Routledge.

Murray, S (2005), 'Brand loyalties: rethinking content within global corporate media', Media Culture \& Society, 27 (3): 415-435.

Owen, B and Wildman, S (1992), Video Economics, Cambridge, Mass: Harvard University Press.

Parker, R (2007), 'Focus: 360-degree commissioning', Broadcast, September $13^{\text {th }} 2007$, at p11.

Patterson, T (2007), Creative Destruction: An Exploratory Look at News on the Internet, Report from the Joan Shorenstein Center on the Press, Politics and Public Policy, NY: Harvard University.

Peacock, A. (1989). Introduction. In Hughes, G. \& Vines, D. (Eds). Deregulation and the Future of Commercial Television (pp. 1-8). David Hume Institute Paper No. 12. Aberdeen: Aberdeen University Press. 
Picard, R (1989), Media Economics: Concepts and Issues. Newbury Park, CA: Sage.

Roscoe, J (2004), 'Multi-Platform Event Television: Reconceptualizing our Relationship with Television', The Communications Review, 7: 363-369.

Schumpeter, J (1942), Capitalism, Socialism and Democracy, Harper: New York.

Shapiro, C and Varian, H (1999), Information Rules: A Strategic Guide to the Network Economy, Boston, MA: Harvard Business School Press.

Slattery, J (2009), 'Where the hell do we go now?', Guardian, Media Supplement, January 5, at p1.

Throsby, David (2001), Economics and Culture, Cambridge: Cambridge University Press.

Towse, R (2010), A Textbook of Cultural Economics, Cambridge: Cambridge University Press.

Thompson, M (2006) 'BBC Creative Future' in Sinclair, C (ed) (2006), Transforming Television: Strategies for Convergence, Glasgow: The Research Centre, pp 10-17.

Williams, R (1981), Culture, London: Fontana.

Wirth, M. \& Bloch, H. (1995), Industrial Organization Theory and Media Industry Analysis, Journal of Media Economics, 8 (2): 15-26.

Ytreberg, E (2009), Extended liveness and eventfulness in multi-platform reality formats, New Media \& Society, 11: 467-485. 